Article

\title{
Spring Failure Analysis of Mining Vibrating Screens: Numerical and Experimental Studies
}

\author{
Yue Liu ${ }^{1, *}$, Guoying Meng ${ }^{2, *}$, Shuangfu Suo ${ }^{1, *}$, Dong $\mathrm{Li}^{3}{ }^{3}$, Aiming Wang ${ }^{2}$, Xiaohan Cheng ${ }^{2}$ \\ and Jie Yang ${ }^{2}$ \\ 1 Department of Mechanical Engineering, State Key Laboratory of Tribology, Tsinghua University, \\ Beijing 100084, China \\ 2 School of Mechanical Electronic \& Information Engineering, China University of Mining \& \\ Technology-Beijing, Beijing 10083, China \\ 3 Department of Intelligent Equipment, Changzhou College of Information Technology, \\ Changzhou 213164, China \\ * Correspondence: liuyue2018@mail.tsinghua.edu.cn (Y.L.); mgy@cumtb.edu.cn (G.M.); \\ sfsuo@tsinghua.edu.cn (S.S.)
}

Received: 25 July 2019; Accepted: 6 August 2019; Published: 7 August 2019

\begin{abstract}
Spring failure is one of the critical causes of the structural damage and low screening efficiency of mining vibrating screens. Therefore, spring failure diagnosis is necessary to prompt maintenance for the safety and reliability of mining vibrating screens. In this paper, a spring failure diagnosis approach is developed. A finite element model of mining vibrating screens is established. Simulations are carried out and the spring failure influence rules of spring failure on the dynamic characteristics of mining vibrating screens are obtained. These influence rules indicate that the amplitude variation coefficients (AVCs) of the four spring seats in the $x, y$, and $z$ directions can reveal two kinds of single spring failure and four kinds of double spring failure, which are useful for diagnosing spring failure. Furthermore, experiments are conducted. Comparison analyses of the experimental results and simulation results indicate that the proposed approach is capable of revealing various kinds of spring failure. Therefore, this approach provides useful information for diagnosing spring failure and guiding technical staff to routinely maintain mining vibrating screens.
\end{abstract}

Keywords: mining vibrating screen; finite element model; spring stiffness decrease; failure diagnosis; amplitude variation coefficient

\section{Introduction}

Mining vibrating screens are widely used for coal mine washing and processing in China [1,2]. Due to difficult working conditions and long-term alternating loads, spring permanent deformation failure of the spring may occur, and this leads to a decrease in spring stiffness. Mining vibrating screens are likely to experience this kind of spring failure during their service lifecycle $[3,4]$. As a result, the stable system becomes unstable. This is one of the major causes of beam damage and material maldistribution [5]. Therefore, spring failure diagnosis is critical for prompt maintenance to keep mining vibrating screens safe and reliable.

Failure diagnosis requires accurate dynamic modeling and system identification [6]. In recent years, many studies have reported on the dynamic modeling [7-10], dynamic design [11-14], dynamic optimization [15-20], particle motion analysis [21-24], and spring failure diagnosis of vibrating screens [25-29]. 
Aimed at spring failure diagnosis, Peng et al. presented a rigid plate structure to describe the isolation system and proposed the method of stiffness identification by stiffness matrix disassembly; their numerical simulation results demonstrated the feasibility of this method [25,26]. Additionally, Peng et al. developed a diagnostic methodology for identifying the stiffness of damping springs with a free response. The asymmetric dynamic model of the vibrating screen with a damping spring fault was established, and the vibration differential equation was derived. Then, the discrete free acceleration response data were processed and subsequently constructed in matrix form to obtain the modified stiffness matrix. Moreover, by disassembling the stiffness matrix and defining the stiffness assurance criterion, the principle and procedures for stiffness identification of a large vibrating screen were summarized. Finally, they carried out an experimental test to verify the validity of the developed method for stiffness identification [27]. Rodriguez et al. developed a two-dimensional, three-degree-of-freedom nonlinear model that considered angular motion and damping, which allowed for the prediction of the behavior of a vibrating screen when there was a reduction in spring stiffness, and they used this model to determine a limit on spring failures before the separation efficiency was affected [28]. Liu et al. proposed a six-degree-of-freedom theoretical rigid body model of a mining vibrating screen and established the dynamic equation in order to explore the dynamic characteristics. Six kinds of spring failure were selected for simulations, and the results indicated that the spring failures led to an amplitude change of the four elastic support points in the $x, y$, and $z$ directions, where the changes depended on certain spring failures. The conclusions provided a theoretical basis for further study and experimentation on spring failure diagnosis for mining vibrating screens [29].

The above studies investigated a few particular cases of mining vibrating screens with spring failures by using theoretical models in which the screen is modelled as a rigid body without structural distortions. However, the mining vibrating screen box is composed of multiple beams and large thin plates, and it produces partial elastic deformation during system vibration. Additionally, spring failures may impact the mining vibrating screen's dynamic characteristics. The finite element method is widely used for dynamics analysis and failure diagnosis [30-35].

The purpose of the present study is to explore the dynamic characteristics of mining vibrating screens with spring failure using the finite element method, as well as to develop a spring failure diagnosis approach. The finite element model is established, and simulations are carried out for extracting the vibration characteristics of the four spring seats, which can reveal spring failure, thereby providing a spring failure diagnosis approach. Moreover, the accuracy of this approach is verified experimentally.

\section{Finite Element Model}

This study uses the SLK3661W mining vibrating screen for the exploration, which is designed symmetrically and installed horizontally, as shown in Figure 1 . The mining vibrating screen vibrates under alternating force, which is created by two exciter eccentric blocks rotating reversely and synchronously. The alternating force excites the mining vibrating screen into linear reciprocating motion. Coal mine materials of different sizes are fed into the loading side and then leap forward and are processed through a specified screen opening on the double deck, before finally being ejected out on the unloading side. 


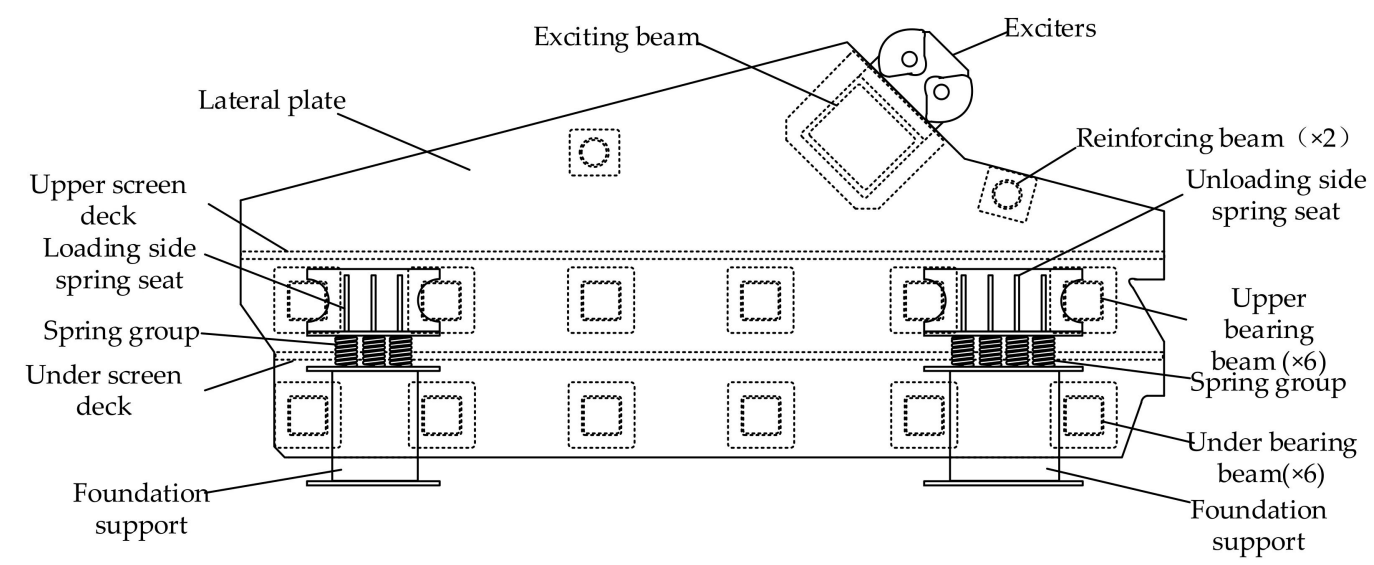

Figure 1. Structures of the SLK3661W mining vibrating screen (lateral view). The left side is the loading side and the right side is the unloading side.

\subsection{Modeling}

In this paper, ANSYS is adopted to establish the finite element model of a mining vibrating screen. The main modeling contents include the following aspects:

- Beam model. The vibrating screen has one exciting beam, two reinforcement beams, and a dozen bearing beams. In order to ensure that the calculation is accurate and it is easy to load the alternating forces, SOLID elements are adopted for the beam models, as shown in Figure 2a-c;

- Lateral plate model. The mining vibrating screen has a pair of lateral plates. The dimensions of a single lateral plate are $7010 \mathrm{~mm} \times 3174 \mathrm{~mm} \times 10 \mathrm{~mm}$; thus, the thickness is far smaller than the length and height. In this paper, SHELL181 elements are used to model the lateral plate, as shown in Figure 2e, to ensure the calculation accuracy and efficiency;

- Bolted connection model. The beam flanges, lateral plates, and spring seats are connected by bolts in practice. In this paper, beam elements are adopted to simulate bolts for improving the calculation efficiency, as shown in Figure 2d. Hard points are created at the bolt positions of all structures, and multiple linear BEAM188 elements are used to connect the mesh nodes around the hard points so as to maintain the same degree of freedom of these hard points, which can reflect the bolted connection relationship;

- $\quad$ Spring seat and spring model. The mining vibrating screen has two loading side spring seats and two unloading side spring seats. Four elastic supports comprised of linear metal cylindrical helical springs are mounted under the spring seats. In this paper, the SHELL181 elements are adopted for modeling the spring seats, and the linear SPRING elements are adopted to simulate each elastic support. The SPRING elements are established at the centre of the spring seat baseplate in three mutually perpendicular directions $(x, y, z)$, and the other end of each SPRING element is fixed, as shown in Figure 2f,g;

- Exciter model. In practice, the mining vibrating screen has two exciters, which are bolted on the exciting beam (region A and region B). Since the exciter mass is much lower than the mining vibrating screen, the inertia of the whole system is not affected by the exciters. Therefore, the point mass units are adopted to simulate the exciter mass of region $A$ and region $B$ in this paper. Meanwhile, the stiffening caused by the exciters is negligible, because it is far less than the system alternating forces. In this paper, the alternating forces are applied on region A and region B. 


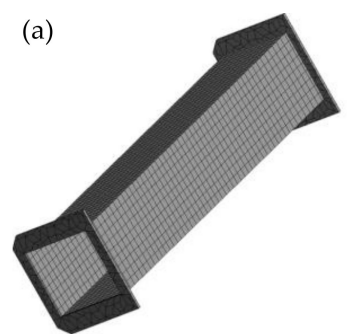

(b)

(e)

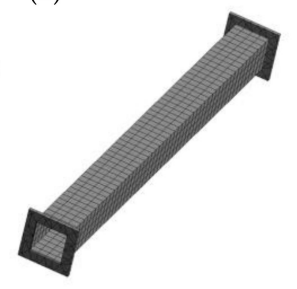

(c)

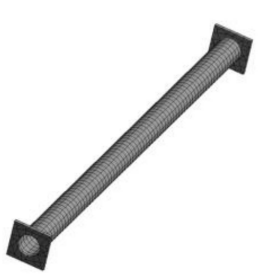

(d)

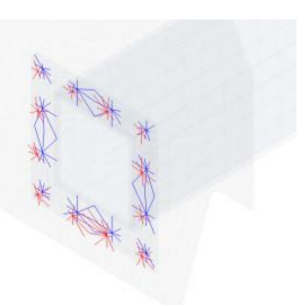

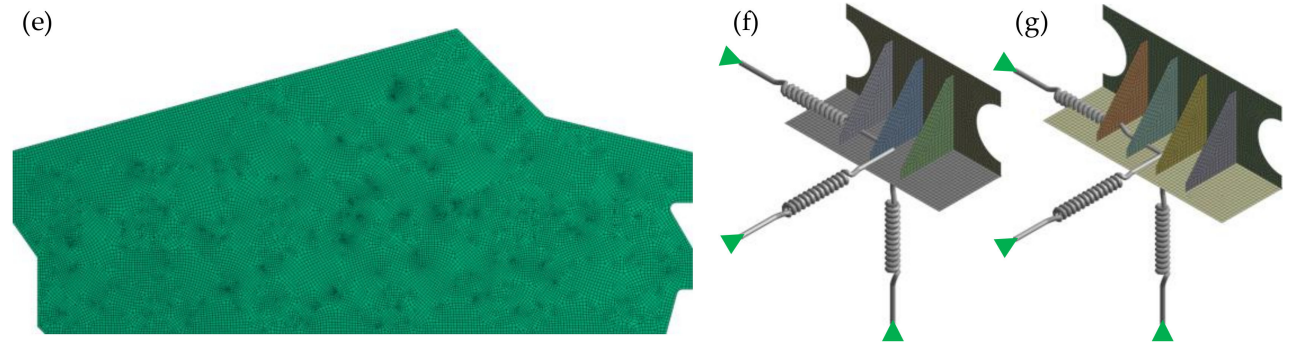

Figure 2. Meshed finite element model of the mining vibrating screen structures: (a) meshed exciting beam, (b) meshed bearing beam, (c) meshed reinforcing beam, (d) bolted connection, (e) meshed lateral plate, (f) loading side spring seat with simplified springs, and (g) unloading side spring seat with simplified springs.

According to the above modeling method, the overall finite element model of a mining vibrating screen can be established, as shown in Figure 3. In this finite element model, the number of finite elements is 39,214 , the number of nodes is 127,932 , the whole system mass is $11,303 \mathrm{~kg}$, and the damping coefficient is 0.04 .
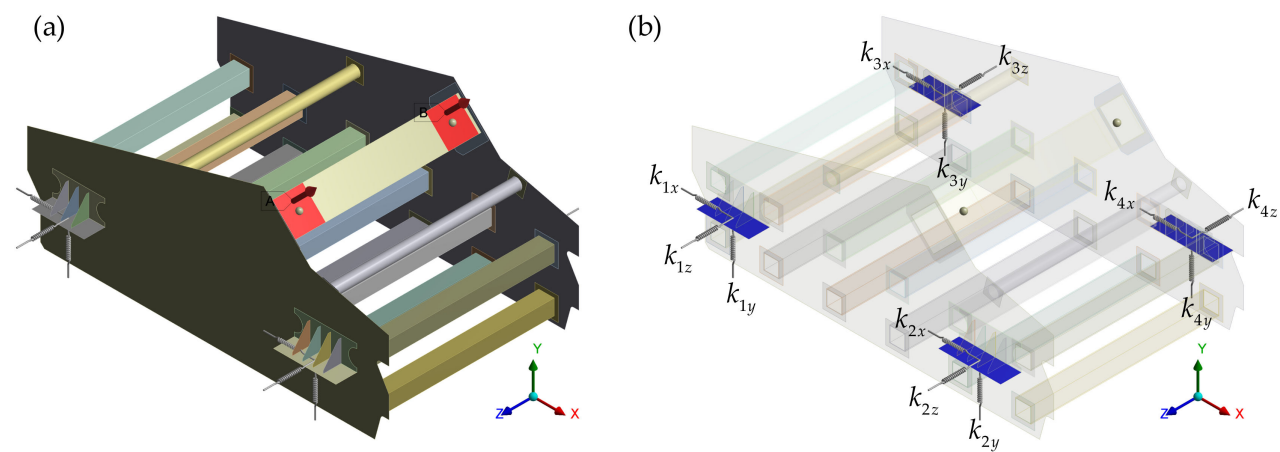

Figure 3. The overall finite element model of the mining vibrating screen. (a) POINT MASS units and alternating forces are applied on region A and region B. (b) Diagram of elastic supports.

According to the system technical descriptions, the elastic support parameters can be obtained, as shown in Table 1. The alternating forces are loaded as simple harmonic forces on POINT MASS in the $x-y$ plane, the amplitude of each sinusoidal force is $450 \mathrm{kN}$, and the force frequency is $14.82 \mathrm{~Hz}$, which is typical of vibrating screen operations.

Table 1. Elastic support simulation parameters table.

\begin{tabular}{ccccc}
\hline Parameters & $k_{1 x} /(\mathrm{N} / \mathrm{m})$ & $k_{2 x} /(\mathrm{N} / \mathrm{m})$ & $k_{3 x} /(\mathrm{N} / \mathrm{m})$ & $k_{4 x} /(\mathrm{N} / \mathrm{m})$ \\
value & 353,010 & 470,680 & 353,010 & 470,680 \\
\hline parameters & $k_{1 y} /(\mathrm{N} / \mathrm{m})$ & $k_{2 y} /(\mathrm{N} / \mathrm{m})$ & $k_{3 y} /(\mathrm{N} / \mathrm{m})$ & $k_{4 y} /(\mathrm{N} / \mathrm{m})$ \\
value & 931,800 & $1,242,400$ & 931,800 & $1,242,400$ \\
\hline parameters & $k_{1 z} /(\mathrm{N} / \mathrm{m})$ & $k_{2 z} /(\mathrm{N} / \mathrm{m})$ & $k_{3 z} /(\mathrm{N} / \mathrm{m})$ & $k_{4 z} /(\mathrm{N} / \mathrm{m})$ \\
value & 353,010 & 470,680 & 353,010 & 470,680 \\
\hline
\end{tabular}




\subsection{Simulation Results}

Simulations were carried out using ANSYS to calculate the system vibration responses. The vibration displacements of the mining vibrating screen were obtained, and the results are displayed in Figure 4.
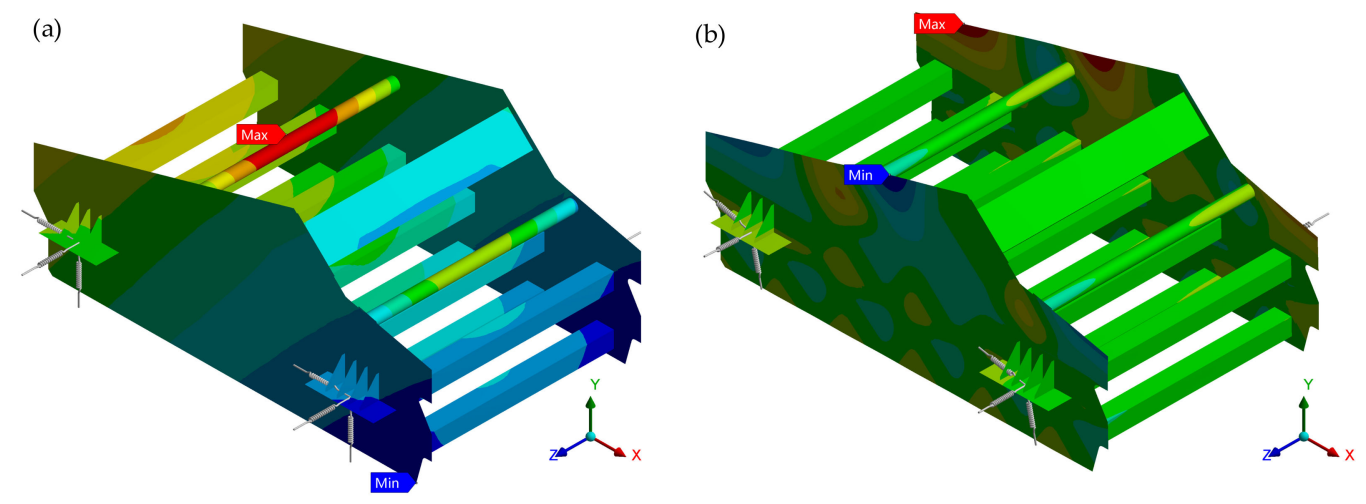

Figure 4. Vibration displacement contour map of the mining vibrating screen. (a) Overall vibration displacement contour map of the overall structure. (b) Lateral vibration displacement contour map.

The overall structure vibration includes the longitudinal vibration (in the $y$ direction) and horizontal vibration (in the $x$ direction). The stable state overall maximum amplitude (peak-to-peak value of displacement) is $11.54 \mathrm{~mm}$, which is located in the middle of the reinforced beam. Meanwhile, the overall minimum amplitude is $8.40 \mathrm{~mm}$, which is located at the bottom of the lateral plate. Furthermore, the mining vibrating screen assembled by multiple beams and plates will produce partial elastic deformation during system vibration. Therefore, the overall structure has lateral vibration (in the $z$ direction), and the maximum amplitude is $0.89 \mathrm{~mm}$, which is located at the upper part of the lateral plate. These vibration amplitudes can meet the work requirements.

The value of $k_{1 y}$ was reduced by $30 \%$ to simulate spring failure, the vibration displacements of the mining vibrating screen were obtained, and the results are displayed in Figure 5.
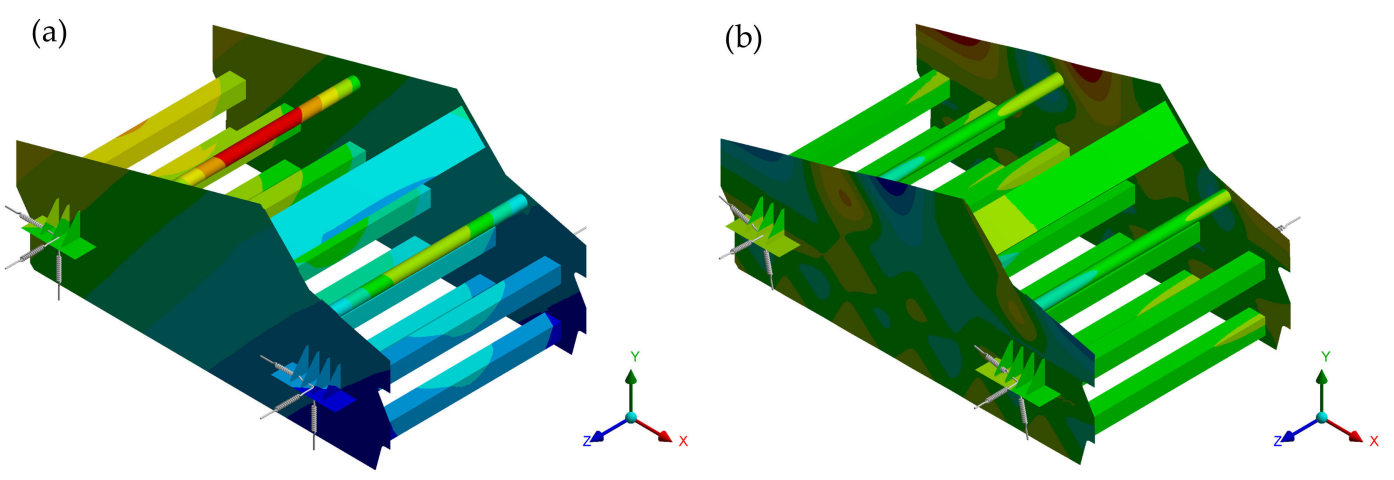

Figure 5. Vibration displacement contour map of the mining vibrating screen with spring failure. (a) Overall vibration displacement contour map of the overall structure. (b) Lateral vibration displacement contour map. 
As shown in Figure 5, the overall structure vibration displacements have changed. The overall maximum displacement is $11.49 \mathrm{~mm}$, the overall minimum displacement is $8.36 \mathrm{~mm}$, and the maximum lateral vibration displacement is $1.26 \mathrm{~mm}$. However, these vibration characteristics may not meet the work requirements, and the lateral vibration displacement must be less than $1 \mathrm{~mm}$ when the mining vibrating screen is working [36].

According to the simulations and analyses above, the results indicate that the whole system vibrations include longitudinal vibration (in the $y$ direction), horizontal vibration (in the $x$ direction), and lateral vibration (in the $z$ direction) under normal conditions. However, the lateral vibration displacements (in the $z$ direction) may increase as a result of spring failure, which cannot meet the work requirements. The system displacements in the established finite element model are sensitive to variable spring stiffness changes.

\section{Spring Failure Analysis}

In order to obtain the influences of spring failure (i.e., stiffness decreases in the $y$ direction) on the mining vibrating screens, the amplitudes of the four spring seats in the $x, y$, and $z$ directions were selected to reflect the system dynamic characteristics in this paper. Furthermore, several kinds of spring failure were selected, as shown in Table 2.

Table 2. Kinds of spring failure.

\begin{tabular}{ccccc}
\hline Kind & $k_{1}$ & $k_{2}$ & $k_{3}$ & $k_{4}$ \\
\hline 1 & failure & normal & normal & normal \\
2 & normal & failure & normal & normal \\
3 & failure & failure & normal & normal \\
4 & failure & normal & failure & normal \\
5 & failure & normal & normal & failure \\
6 & normal & failure & normal & failure \\
\hline
\end{tabular}

In [29], the stiffness variation coefficient (SVC) $\Delta k_{i}$ and the amplitude variation coefficient (AVC) $\Delta \lambda_{i d}$ are proposed for normalization of the stiffness and amplitude change, namely,

$$
\begin{gathered}
\Delta k_{i}=\frac{k_{i j 0}-k_{i j}}{k_{i j 0}} \times 100 \%, \quad(i=1,2,3,4 ; \quad j=1,2, \ldots, n) \\
\Delta \lambda_{i d}=\frac{\lambda_{i d 0}-\lambda_{i d}}{\lambda_{i d 0}} \times 100 \%, \quad(i=1,2,3,4 ; \quad d=x, y, z)
\end{gathered}
$$

where $i$ is the elastic support sequence number, $j$ is the stiffness sequence number, $d$ is one of the three directions, $k_{i j 0}$ is the normal spring stiffness in the $y$ direction, $k_{i j}$ is the failure spring stiffness in the $y$ direction, $\lambda_{i d 0}$ is the normal amplitude of one spring seat, and $\lambda_{i d}$ is the various amplitudes of the same spring seat.

\subsection{Single Spring Failure Analysis}

In the case of $k_{1}$ failure, the SVC $\Delta k_{1}$ is changed from $0 \%$ to $30 \%$, and the AVCs of each spring seat in the $x, y$, and $z$ directions are obtained and presented in Figure 6. 

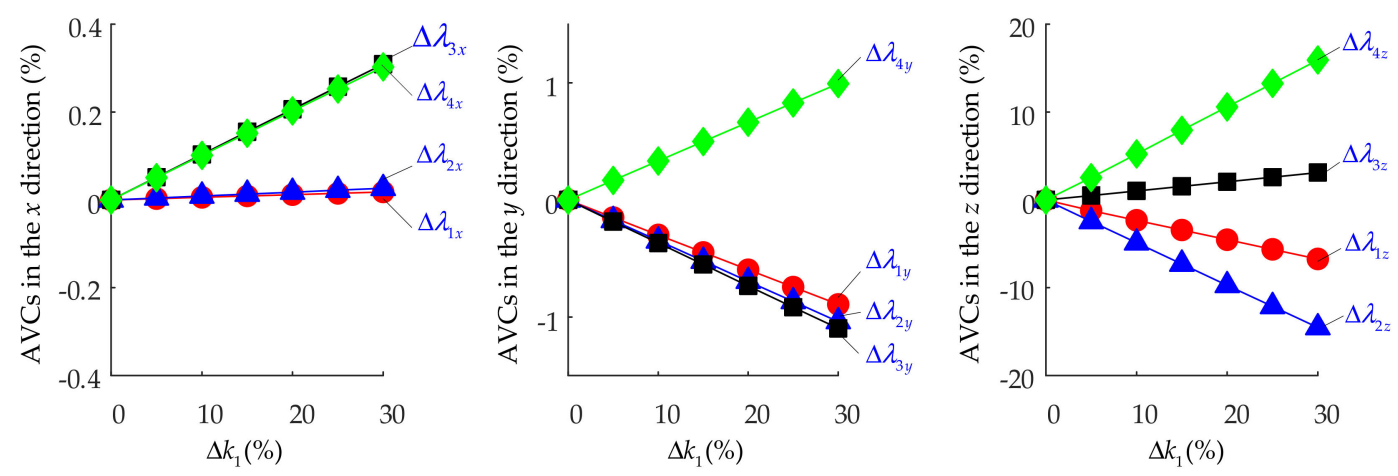

Figure 6. The amplitude variation coefficient (AVC) curves of each spring seat in the $x, y$, and $z$ directions in the case of $k_{1}$ failure.

As shown in Figure 6, if the SVC $\Delta k_{1}$ increases, all AVCs in the $x$ direction increase. In the $y$ direction, the AVC of spring seat 4 increases, and the other AVCs decrease. In the $z$ direction, the AVCs of spring seat 3 and 4 increase, and the AVCs of spring seat 1 and 2 decrease. In the case of $\Delta k_{1}=30 \%$, the absolute value of AVCs in the $z$ direction is less than $15.93 \%$, the absolute value of AVCs in the $y$ direction is less than $1.10 \%$, and the absolute value of AVCs in the $x$ direction is less than $0.31 \%$.

\subsection{Double Spring Failure Analysis}

In the case of $k_{1}$ and $k_{2}$ failure, the spring SVCs $\Delta k_{1}$ and $\Delta k_{2}$ are changed from $0 \%$ to $30 \%$, and the AVCs of all four spring seats in all directions change together, as shown in Figure 7.
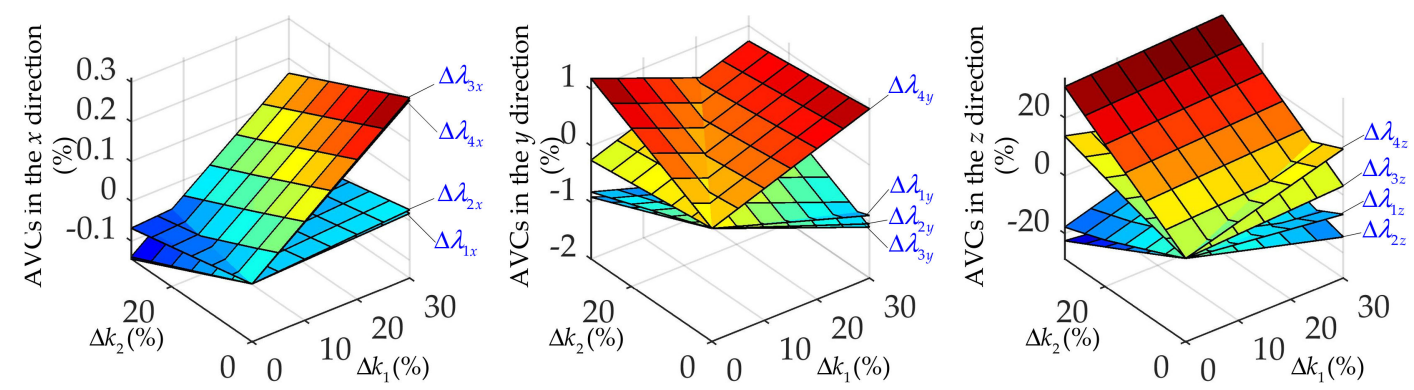

Figure 7. The amplitude variation coefficient (AVC) surfaces of four spring seats in the $x, y$, and $z$ directions.

As shown in Figure 7, the AVC of each spring seat in the $x$ direction decreases, increases, or stays the same (i.e., indeterminate) with the coupling influence of double spring failure. In the $y$ direction, the AVCs of spring seat 1 and 2 decrease, and the AVCs of spring seat 3 and 4 decrease, increase, or stay the same (i.e., indeterminate). In the $z$ direction, the AVCs of spring seat 1 decrease and the AVCs of spring seat 3 increase, while the other AVCs decrease, increase, or stay the same (i.e., indeterminate). Furthermore, the absolute value of AVCs in the $z$ direction is less than $15.93 \%$, the absolute value of AVCs in the $y$ direction is less than $1.10 \%$, and the absolute value of AVCs in the $x$ direction is less than $0.31 \%$. With the coupling influence of double spring failure, the AVCs in the $z$ direction change a lot, but the AVCs in the $x$ and $y$ direction change a little.

\subsection{Discussion}

More analyses with different kinds of spring failure were carried out, and the influence rules among the SVCs and the AVCs were obtained and are listed in Table 3. 
Table 3. The influence rules among stiffness variation coefficients (SVCs) and amplitude variation coefficients (AVCs) with six kinds of spring failure.

\begin{tabular}{|c|c|c|c|c|c|c|c|c|c|c|c|c|}
\hline \multirow{2}{*}{$\begin{array}{c}\text { Failure } \\
\text { Kind }\end{array}$} & \multicolumn{12}{|c|}{ AVCs } \\
\hline & $\Delta \lambda_{1 x}$ & $\Delta \lambda_{2 x}$ & $\Delta \lambda_{3 x}$ & $\Delta \lambda_{4 x}$ & $\Delta \lambda_{1 y}$ & $\Delta \lambda_{2 y}$ & $\Delta \lambda_{3 y}$ & $\Delta \lambda_{4 y}$ & $\Delta \lambda_{1 z}$ & $\Delta \lambda_{2 z}$ & $\Delta \lambda_{3 z}$ & $\Delta \lambda_{4 z}$ \\
\hline 1 & +1 & + & + & + & -2 & - & - & + & - & - & + & + \\
\hline 2 & - & - & - & - & - & - & + & - & - & + & + & - \\
\hline 3 & $\pm^{3}$ & \pm & \pm & \pm & - & - & \pm & \pm & - & \pm & + & \pm \\
\hline 4 & + & + & + & + & - & \pm & - & \pm & \pm & \pm & \pm & \pm \\
\hline 5 & \pm & \pm & \pm & \pm & \pm & - & - & \pm & \pm & - & \pm & + \\
\hline 6 & - & - & - & - & \pm & - & \pm & - & \pm & \pm & \pm & \pm \\
\hline
\end{tabular}

As shown in Table 3, the SVCs under different spring failures have different influences on the AVCs in the $x, y$, and $z$ directions. Hence, the influence rules among SVCs and AVCs with six kinds of spring failure can be summarized as follows:

- Under failure kind 1 condition: In the $x$ direction, all AVCs will increase. In the $y$ direction, the AVC $\Delta \lambda_{1 y}, \Delta \lambda_{2 y}$, and $\Delta \lambda_{3 y}$ will decrease, while AVC $\Delta \lambda_{4 y}$ will decrease. In the $z$ direction, the AVC $\Delta \lambda_{3 z}$ and $\Delta \lambda_{4 z}$ will increase, while the AVC $\Delta \lambda_{1 z}$ and $\Delta \lambda_{2 z}$ will decrease;

- Under failure kind 2 condition: In the $x$ direction, all AVCs will decrease. In the $y$ direction, the AVC $\Delta \lambda_{1 y}, \Delta \lambda_{2 y}$, and $\Delta \lambda_{4 y}$ will decrease, while the AVC $\Delta \lambda_{3 y}$ will decrease. In the $z$ direction, the AVC $\Delta \lambda_{2 z}$ and $\Delta \lambda_{3 z}$ will increase, while the AVC $\Delta \lambda_{1 z}$ and $\Delta \lambda_{4 z}$ will decrease;

- Under failure kind 3 condition: In the $x$ direction, all AVCs will be indeterminate. In the $y$ direction, the AVC $\Delta \lambda_{1 y}$ and $\Delta \lambda_{2 y}$ will decrease, while the AVC $\Delta \lambda_{3 y}$ and $\Delta \lambda_{4 y}$ will be indeterminate. In the $z$ direction, the AVC $\Delta \lambda_{1 z}$ will decrease, the AVC $\Delta \lambda_{3 z}$ will increase, and $\Delta \lambda_{2 z}$ and $\Delta \lambda_{4 z}$ will be indeterminate;

- Under failure kind 4 condition: In the $x$ direction, all AVCs will increase. In the $y$ direction, the AVC $\Delta \lambda_{1 y}$ and $\Delta \lambda_{3 y}$ will decrease, and the AVC $\Delta \lambda_{2 y}$ and $\Delta \lambda_{4 y}$ will be indeterminate. In the $z$ direction, all AVCs will be indeterminate;

- Under failure kind 5 condition: In the $x$ direction, all AVCs will be indeterminate. In the $y$ direction, the AVC $\Delta \lambda_{2 y}$ and $\Delta \lambda_{3 y}$ will decrease, and the AVC $\Delta \lambda_{1 y}$ and $\Delta \lambda_{4 y}$ will be indeterminate. In the $z$ direction, the AVC $\Delta \lambda_{2 z}$ will decrease, the AVC $\Delta \lambda_{4 z}$ will increase, and the AVC $\Delta \lambda_{1 z}$ and $\Delta \lambda_{3 z}$ will be indeterminate;

- Under failure kind 6 condition: In the $x$ direction, all AVCs will decrease. In the $y$ direction, the AVC $\Delta \lambda_{2 y}$ and $\Delta \lambda_{4 y}$ will decrease, and the AVC $\Delta \lambda_{1 y}$ and $\Delta \lambda_{3 y}$ will be indeterminate. In the $z$ direction, all AVCs will be indeterminate.

The influence rules listed above indicate that each kind of spring failure leads to one specific influence rule on the AVCs of the four spring seats in the $x, y$, and $z$ directions. Hence, a spring failure diagnosis approach can be developed based on the knowledge that the mining vibrating screen dynamic characteristics can reveal certain kinds of spring failure.

\section{Validation of Developed Diagnosis Approach}

Experiments were conducted on a SLK3661W vibrating screen with YHJ(C) mining portable vibration data acquisition instruments and GBC1000 mining intrinsically safe vibration sensors, as shown in Figure 8. Three acceleration sensors were mounted orthogonally on each spring seat to obtain the longitudinal vibration (in the $y$ direction), horizontal vibration (in the $x$ direction), and lateral vibration (in the $z$ direction) acceleration signals individually. Meanwhile, all acceleration signals were acquired and saved with data acquisition instruments. 


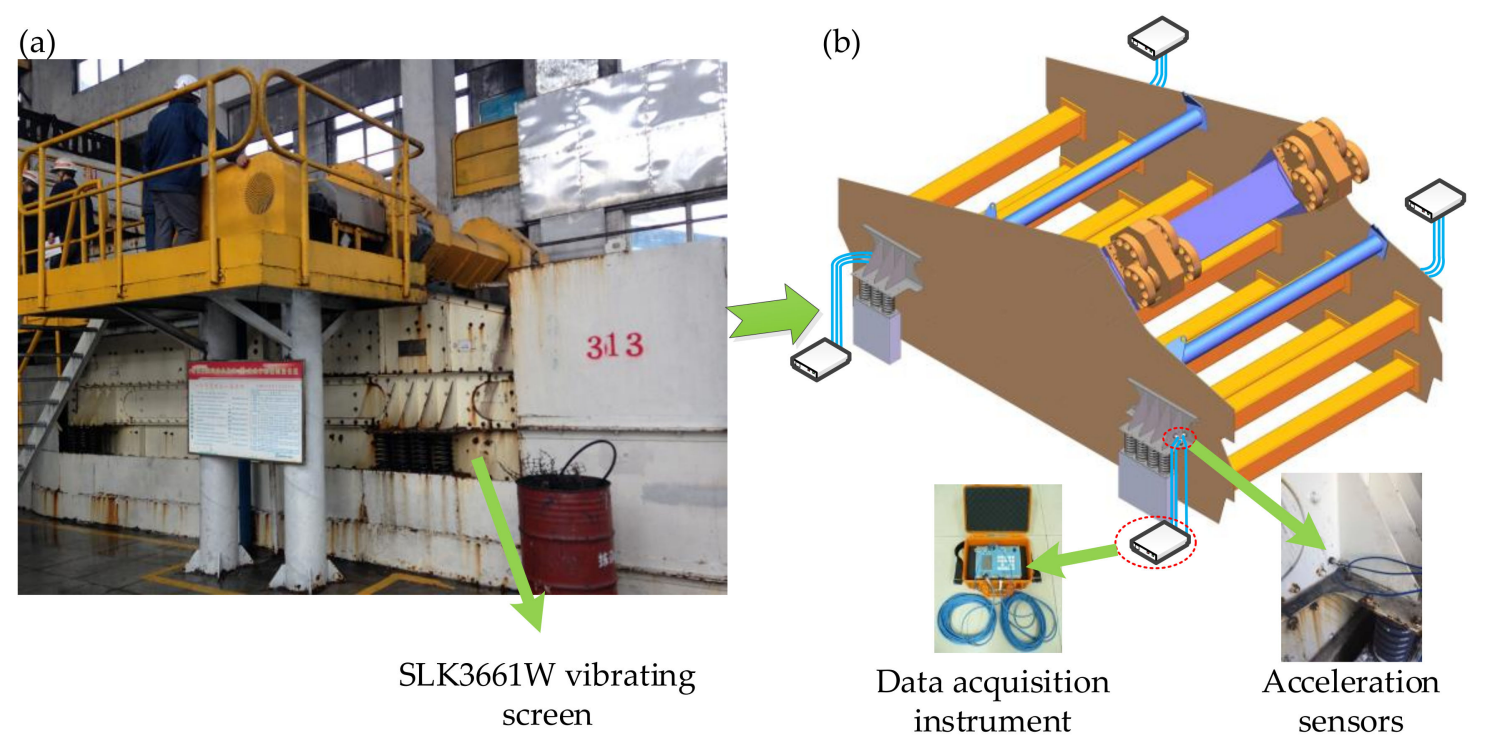

Figure 8. Experimental setup. (a) The SLK3661W vibrating screen applied in the coal washery. (b) Acceleration sensors and data acquisition instruments used in experiments.

The main parameters of data acquisition are shown in Table 4.

Table 4. The main parameters of data acquisition.

\begin{tabular}{cc}
\hline Parameters & Value/Range \\
\hline Sample frequency & $2500 \mathrm{~Hz}$ \\
Sampling resolution & 16 \\
Frequency range & $1-10 \mathrm{kHz}$ \\
Signal amplification ratio & $1: 3$ \\
Output voltage range & $\pm 5000 \mathrm{mV}$ \\
Acceleration range & $0-50 \mathrm{~g}$ \\
Sensor sensitivity & $5 \mathrm{mV} / \mathrm{ms}^{-2}$ \\
\hline
\end{tabular}

Then, the acquisition data were loaded into a computer in the laboratory for data processing with MATLAB. The displacements were calculated from the accelerations by using numerical double integral and detrend operations. For example, the acceleration and displacement curves in the $x, y$, and $z$ directions of spring seat 2 under normal conditions are shown in Figure 9.
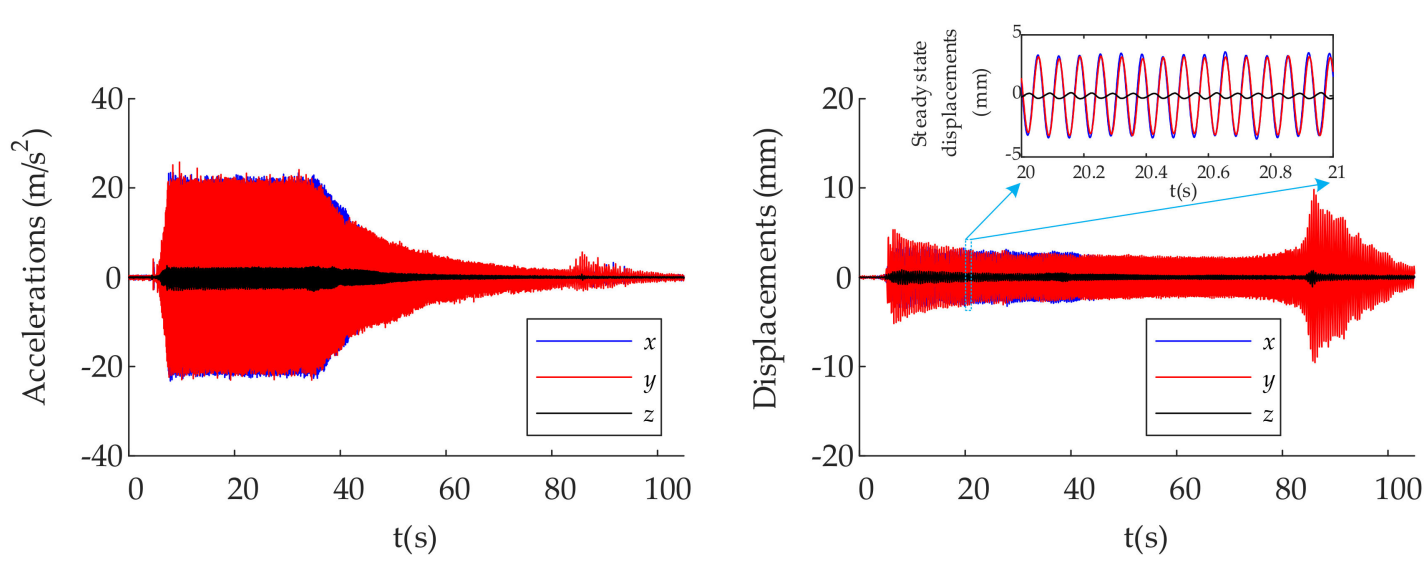

Figure 9. Acceleration and displacement curves in the $x, y$, and $z$ directions of spring seat 2 under normal conditions, including the steady state displacement curves during 20-21 s. 
As shown in Figure 9, the vibrations of the mining vibrating screen include three states:

- Start state. The driving motor causes the mining vibrating screen to vibrate, and the accelerations and displacements rapidly increase. In this state, as the motor speed increases, the mining vibrating screen passes through the resonance region quickly;

- Steady state. The accelerations and displacements gradually change into stable ranges. In this state, the system does not resonate, so it is suitable for long-term stable working;

- Outage state. The accelerations and displacements decrease gradually at first, then increase for a period of time, and finally decrease to zero. In this state, as the motor speed decreases, resonance occurs when the system passes through the resonance region. The mining vibrating screen halts at last.

After data processing, the steady state amplitudes of the four spring seats in the $x, y$, and $z$ directions under normal conditions were obtained, as shown in Table 5.

Table 5. The steady state amplitudes of four spring seats in the $x, y$, and $z$ directions under normal conditions.

\begin{tabular}{ccccc}
\hline \multirow{2}{*}{ Directions } & \multicolumn{4}{c}{ Amplitudes (mm) } \\
\cline { 2 - 5 } & Spring Seat 1 & Spring Seat 2 & Spring Seat 3 & Spring Seat 4 \\
\hline$x$ & 6.271 & 6.258 & 6.185 & 6.202 \\
$y$ & 6.613 & 6.096 & 6.694 & 6.116 \\
$z$ & 0.534 & 0.712 & 0.624 & 0.867 \\
\hline
\end{tabular}

Furthermore, springs with different sizes were adopted as the failure springs with a $20 \%$ decrease in longitudinal ( $y$ direction) stiffness; that is, the SVC was $20 \%$. According to Table 2, six spring failure kinds were selected for conducting the spring failure experiments. After data acquisition and data processing, the steady state amplitudes of four spring seats in the $x, y$, and $z$ directions under the spring failure condition were obtained. Meanwhile, the AVCs of each spring seat in the $x, y$, and $z$ directions could be calculated as experimental results according to Formula (2). Therefore, the experimental results could be compared with the simulation results, as shown in Figures 10-15.

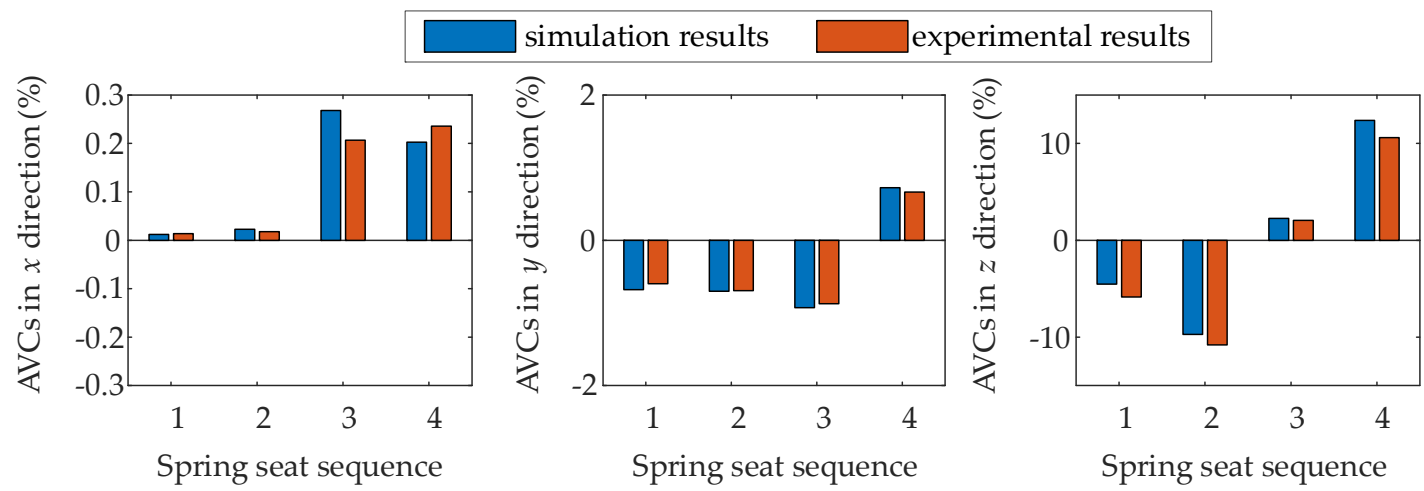

Figure 10. The amplitude variation coefficients (AVCs) of each spring seat in the $x, y$, and $z$ directions under spring failure kind 1 , including the simulation results and experimental results. 


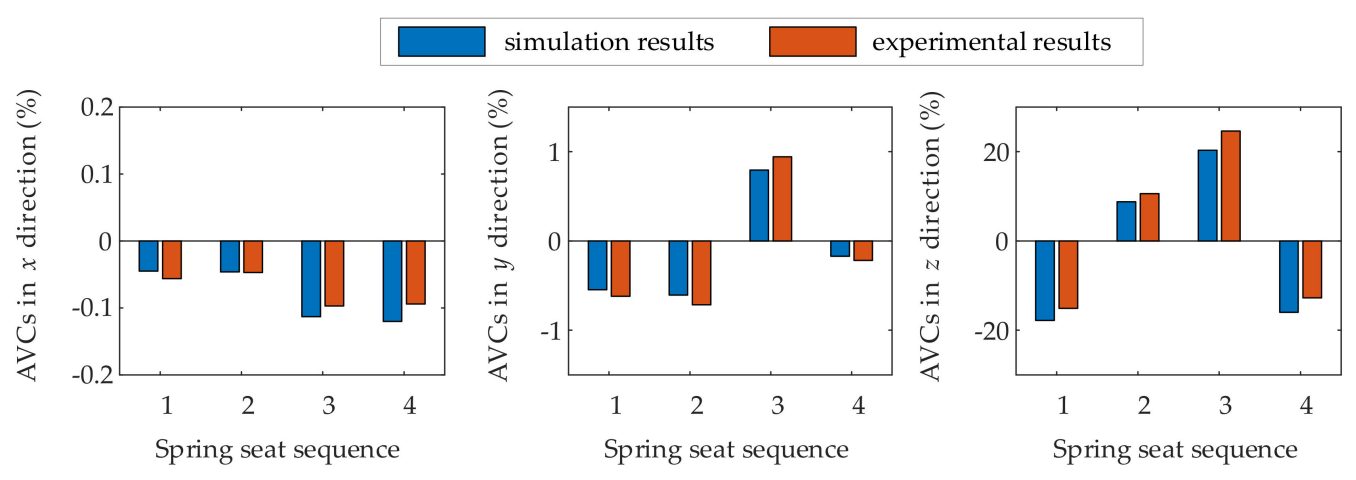

Figure 11. The amplitude variation coefficients (AVCs) of each spring seat in the $x, y$, and $z$ directions under spring failure kind 2, including the simulation results and experimental results.

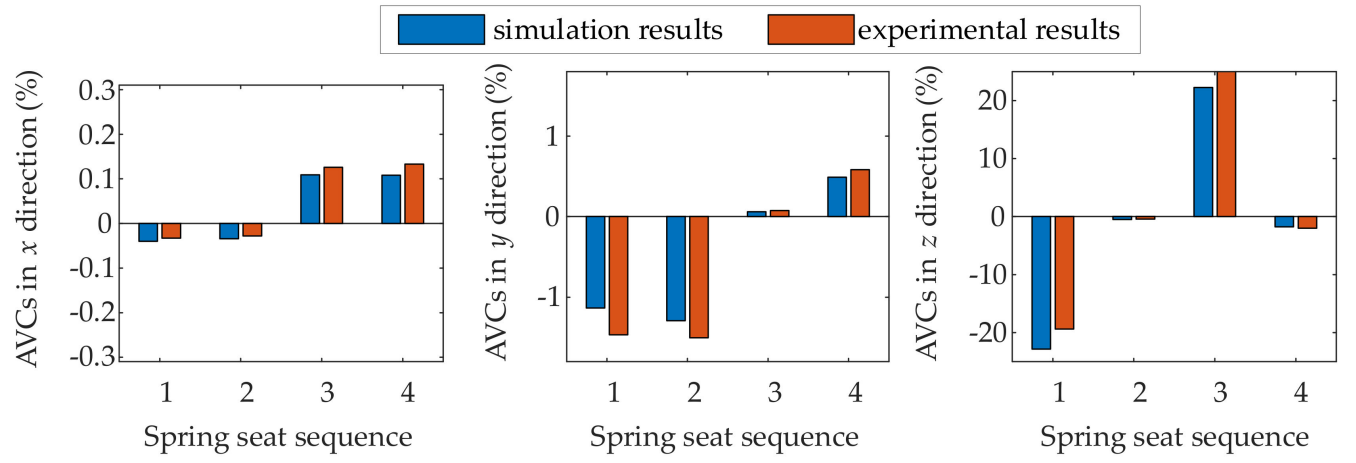

Figure 12. The amplitude variation coefficients (AVCs) of each spring seat in the $x, y$, and $z$ directions under spring failure kind 3 , including the simulation results and experimental results.

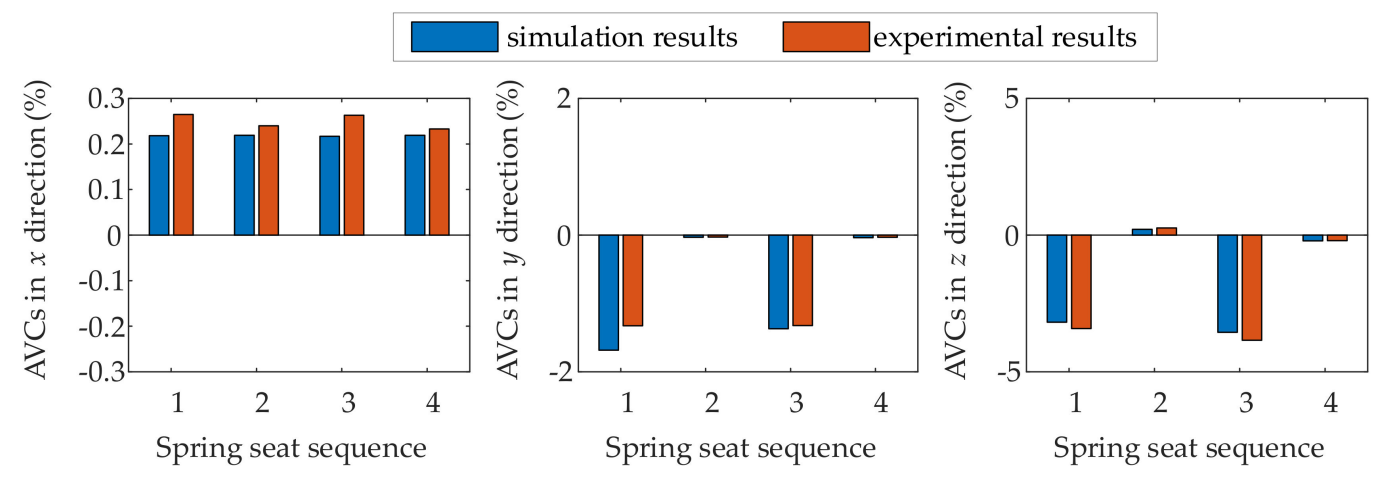

Figure 13. The amplitude variation coefficients (AVCs) of each spring seat in the $x, y$, and $z$ directions under spring failure kind 4 , including the simulation results and experimental results.

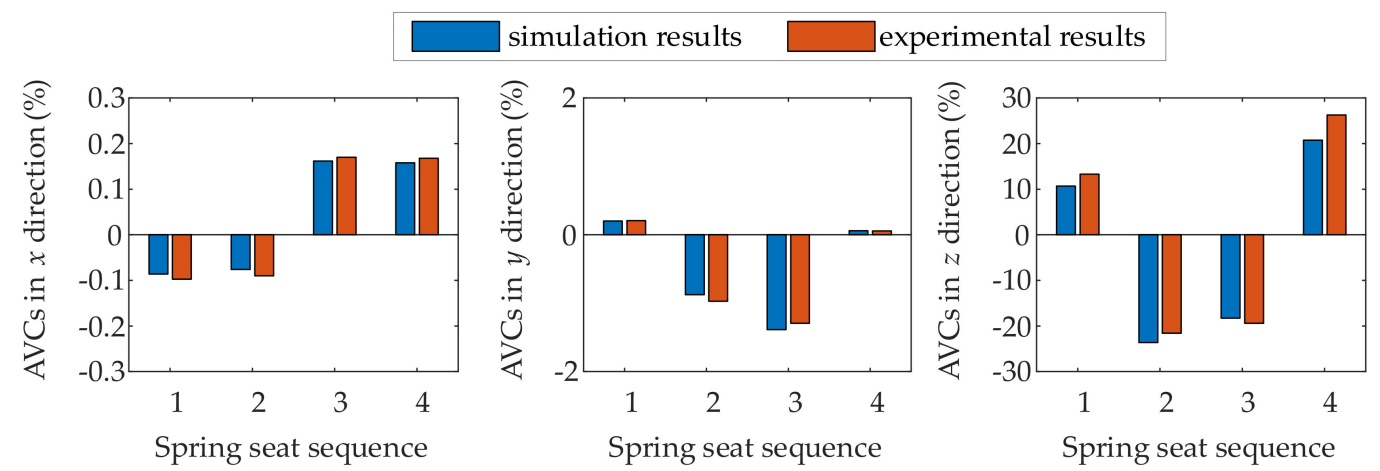

Figure 14. The amplitude variation coefficients (AVCs) of each spring seat in the $x, y$, and $z$ directions under spring failure kind 5, including the simulation results and experimental results. 


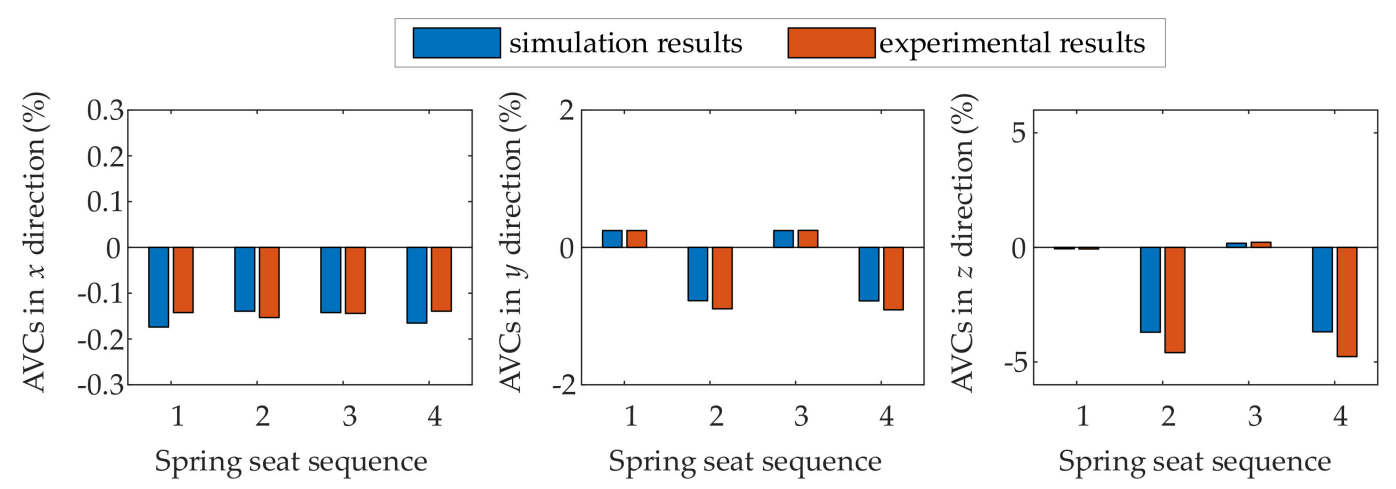

Figure 15. The amplitude variation coefficients (AVCs) of each spring seat in the $x, y$, and $z$ directions under spring failure kind 6 , including the simulation results and experimental results.

The results indicate that the AVCs in the $z$ direction change significantly under the influence of spring failure, whereas the AVCs in the $x$ and $y$ directions change little. Moreover, the simulations and the experimental results are close, including AVC values and change rules. Observed differences are caused by simplifications of the mining vibrating screen during modeling, which inevitably results in differences in the system parameters. The developed approach is verified as feasible for spring failure diagnosis.

\section{Conclusions}

This study reports a proposed approach for the spring failure diagnosis of mining vibrating screens by using numerical and experimental studies. The following conclusions are drawn. The spring failures of spring stiffness decrease have a specific influence on the mining vibrating screen dynamic characteristics. The system displacements in the established finite element model are sensitive to variable spring stiffness changes. The spring failure influence rules obtained by numerical simulations indicate that the AVCs of the four spring seats in the $x, y$, and $z$ directions may decrease, increase, or stay the same (i.e., indeterminate) under different spring failures. Therefore, the AVCs can reveal single spring failure and double spring failure, which provides a promising approach for spring failure diagnosis. Furthermore, the accuracy of this approach has been experimentally verified. The key of the approach lies in extracting information from orthogonal dynamic displacements to reveal the spring failure, namely obtaining the AVCs of the four spring seats in the $x, y$, and $z$ directions. This information provides guidance for the routine maintenance of mining vibrating screens. However, further work will be required to identify whether this novel finding can be extrapolated to structural health monitoring and predictive maintenance.

Author Contributions: Conceptualization, Y.L. and G.M.; Methodology, Y.L., S.S., A.W., and D.L.; Validation, Y.L. and X.C.; Writing-Original Draft Preparation, Y.L.; Writing-Review and Editing, Y.L., G.M., and S.S.; and Visualization, Y.L. and J.Y.

Funding: This research was supported by the National key research and development program of China [grant number 2016YFC0600900]; the National Natural Science Foundation of China [grant number U13611151]; and the Yue Qi Distinguished Scholar Project, China University of Mining \& Technology, Beijing.

Conflicts of Interest: The authors declare no conflicts of interest. 


\section{Abbreviations}

The list of symbols is as follows:

$x \quad$ The $x$ direction

$y \quad$ The $y$ direction

$z \quad$ The $z$ direction

$i \quad$ The elastic support sequence number

$j \quad$ The spring stiffness sequence number

$d \quad$ One of the $x, y$, and $z$ directions

$k_{i j 0} \quad$ Normal spring stiffness in the $y$ direction

$k_{i j} \quad$ Failure spring stiffness in the $y$ direction

$\Delta k_{i} \quad$ Stiffness variation coefficient (SVC)

$\lambda_{i d 0} \quad$ Normal amplitude

$\lambda_{i d} \quad$ Failure amplitude

$\Delta \lambda_{i d} \quad$ Amplitude variation coefficient (AVC)

\section{References}

1. Peng, L.P.; Jiang, H.S.; Chen, X.H.; Liu, D.Y.; Feng, H.H.; Zhang, L.; Zhao, Y.M.; Liu, C.S. A review on the advanced design techniques and methods of vibrating screen for coal preparation. Powder Technol. 2019, 347, 136-147. [CrossRef]

2. Yang, X.D.; Wu, J.D.; Jiang, H.S.; Qiu, W.Q.; Liu, C.S. Dynamic Modeling and Parameters Optimization of Large Vibrating Screen with Full Degree of Freedom. Shock Vib. 2019, 12. [CrossRef]

3. Makinde, O.A.; Ramatsetse, B.I.; Mpofu, K. Review of vibrating screen development trends: Linking the past and the future in mining machinery industries. Int. J. Miner. Process. 2015, 145, 17-22. [CrossRef]

4. Legendi, A.; Rece, L.; Pironea, A.D.B.; Florescu, V. Innovative Calculation Method of the Productivity of Vibrating Screens Used in Mineral Aggregates Sorting. Rom. J. Transp. Infrastruct. 2018, 7, 1-13. [CrossRef]

5. Liu, Y. Study on the Dynamic Characteristic and Experiments of Permanent Deformation Failure of Mining Vibrating Screen Springs. Ph.D. Thesis, China University of Mining \& Technology-Beijing, Beijing, China, 2017.

6. Wang, A.; Cheng, X.; Meng, G.; Xia, Y.; Wo, L.; Wang, Z. Dynamic analysis and numerical experiments for balancing of the continuous single-disc and single-span rotor-bearing system. Mech. Syst. Signal Procces. 2017, 86, 151-176. [CrossRef]

7. Moncada, M.; Rodriguez, C.G. Dynamic Modeling of a Vibrating Screen Considering the Ore Inertia and Force of the Ore over the Screen Calculated with Discrete Element Method. Shock Vib. 2018, 13. [CrossRef]

8. Slepyan, L.I.; Slepyan, V.I. Coupled mode parametric resonance in a vibrating screen model. Mech. Syst. Signal Procces. 2014, 43, 295-304. [CrossRef]

9. Trumic, M.; Magdalinovic, N. New model of screening kinetics. Miner. Eng. 2011, 24, 42-49. [CrossRef]

10. Makinde, O.A.; Mpofu, K.; Ramatsetse, B.I.; Adeyeri, M.K.; Ayodeji, S.P. A maintenance system model for optimal reconfigurable vibrating screen management. J. Ind. Eng. Int. 2018, 14, 521-535. (In German) [CrossRef]

11. Baragetti, S. Innovative structural solution for heavy loaded vibrating screens. Miner. Eng. 2015, 84, 15-26. [CrossRef]

12. Xiao, J.; Tong, X. Characteristics and efficiency of a new vibrating screen with a swing trace. Particuology 2013, 11, 601-606. [CrossRef]

13. Song, B.C.; Liu, C.S.; Peng, L.P.; Li, J. Dynamic analysis of new kind elastic screen surface with multi degree of freedom and experimental validation. J. Cent. South Univ. 2015, 22, 1334-1341. [CrossRef]

14. Li, Z.F.; Tong, X.; Zhou, B.; Ge, X.L.; Ling, J.X. Design and Efficiency Research of a New Composite Vibrating Screen. Shock Vib. 2018, 8. [CrossRef]

15. Baragetti, S.; Villa, F. A dynamic optimization theoretical method for heavy loaded vibrating screens. Nonlinear Dyn. 2014, 78, 609-627. [CrossRef]

16. Peng, L.P.; Liu, C.S.; Song, B.C.; Wu, J.D.; Wang, S. Improvement for design of beam structures in large vibrating screen considering bending and random vibration. J. Cent. South Univ. 2015, 22, 3380-3388. [CrossRef] 
17. Li, Z.; Tong, X. Modeling and parameter optimization for vibrating screens based on AFSA-SimpleMKL. Chin. J. Eng. Des. 2016, 23, 181-187.

18. Wu, X.Q.; Li, Z.F.; Xia, H.H.; Tong, X. Vibration Parameter Optimization of a Linear Vibrating Banana Screen Using DEM 3D Simulation. J. Eng. Technol. Sci. 2018, 50, 346-363. [CrossRef]

19. Lyashenko, V.I.; Dyatchin, V.Z.; Franchuk, V.P. Improvement of vibrating feeders-screens for mining and metallurgical industry. Izvestiya vysshikh uchebnykh zavedenii. Chernaya Metall. 2018, 61, 470-477.

20. Li, Z.F.; Li, K.Y.; Ge, X.L.; Tong, X. Performance optimization of banana vibrating screens based on PSO-SVR under DEM simulations. J. Vibroeng. 2019, 21, 28-39.

21. Dong, K.J.; Wang, B.; Yu, A.B. Modeling of Particle Flow and Sieving Behavior on a Vibrating Screen: From Discrete Particle Simulation to Process Performance Prediction. Ind. Eng. Chem. Res. 2013, 52, 11333-11343. [CrossRef]

22. Jiang, H.S.; Zhao, Y.M.; Duan, C.L.; Yang, X.L.; Liu, C.S.; Wu, J.D.; Qiao, J.P.; Diao, H.R. Kinematics of variable-amplitude screen and analysis of particle behavior during the process of coal screening. Powder Technol. 2017, 306, 88-95. [CrossRef]

23. Wang, Z.Q.; Peng, L.P.; Zhang, C.L.; Qi, L.; Liu, C.S.; Zhao, Y.M. Research on impact characteristics of screening coals on vibrating screen based on discrete-finite element method. Energy Sources Part A Recovery Util. Environ. Effects 2019, 14. [CrossRef]

24. Jiang, Y.Z.; He, K.F.; Dong, Y.L.; Yang, D.L.; Sun, W. Influence of Load Weight on Dynamic Response of Vibrating Screen. Shock Vib. 2019, 8. [CrossRef]

25. Peng, L.P.; Liu, C.S.; Li, J.; Wang, H. Static-deformation based fault diagnosis for damping spring of large vibrating screen. J. Cent. South Univ. 2014, 21, 1313-1321. [CrossRef]

26. Peng, L.P.; Liu, C.S.; Wu, J.D.; Wang, S. Stiffness identification of four-point-elastic-support rigid plate. J. Cent. South Univ. 2015, 22, 159-167. [CrossRef]

27. Peng, L.; Liu, C.; Wang, H. Health identification for damping springs of large vibrating screen based on stiffness identification. J. China Coal Soc. 2016, 41, 1568-1574.

28. Rodriguez, C.G.; Moncada, M.A.; Dufeu, E.E.; Razeto, M.I. Nonlinear Model of Vibrating Screen to Determine Permissible Spring Deterioration for Proper Separation. Shock Vib. 2016, 2016, 1-7. [CrossRef]

29. Liu, Y.; Suo, S.; Meng, G.; Shang, D.; Bai, L.; Shi, J. A Theoretical Rigid Body Model of Vibrating Screen for Spring Failure Diagnosis. Mathematics 2019, 7, 246. [CrossRef]

30. Fan, Y.; Collet, M.; Ichchou, M.; Li, L.; Bareille, O.; Dimitrijevic, Z. Energy flow prediction in built-up structures through a hybrid finite element/wave and finite element approach. Mech. Syst. Signal Procces. 2016, 66, 137-158. [CrossRef]

31. Wang, Y.; Liang, M.; Xiang, J. Damage detection method for wind turbine blades based on dynamics analysis and mode shape difference curvature information. Mech. Syst. Signal Procces. 2014, 48, 351-367. [CrossRef]

32. Wang, T.Y.; Han, Q.K.; Chu, F.L.; Feng, Z.P. Vibration based condition monitoring and fault diagnosis of wind turbine planetary gearbox: A review. Mech. Syst. Signal Procces. 2019, 126, 662-685. [CrossRef]

33. Xie, Y.; Chen, P.; Li, F.; Liu, H.S. Electromagnetic forces signature and vibration characteristic for diagnosis broken bars in squirrel cage induction motors. Mech. Syst. Signal Procces. 2019, 123, 554-572. [CrossRef]

34. Bak, Ł.; Noga, S.; Skrzat, A.; Stachowicz, F. Dynamic analysis of vibrating screener system. J. Phys. Conf. Ser. 2013, 451, 1-7. [CrossRef]

35. Bak, Ł.; Noga, S.; Stachowicz, F. The experimental investigation of the screen operation in the parametric resonance conditions. Acta Mech. Autom. 2015, 9, 191-194. [CrossRef]

36. Ministry of Industry and Information Technology of the People's Republic of China. Jb/t 7892-2010, Linear Vibrating Screen with Box Vibrator; China Machine Press: Beijing, China, 2010.

(C) 2019 by the authors. Licensee MDPI, Basel, Switzerland. This article is an open access article distributed under the terms and conditions of the Creative Commons Attribution (CC BY) license (http://creativecommons.org/licenses/by/4.0/). 